\title{
AUTOMAÇÃO DE REATOR DE FERMENTAÇÃO EM ESTADO SÓLIDO PARA SÍNTESE DE ENZIMAS
}

\section{AUTOMATION OF SOLID STATE FERMENTATION REACTOR FOR ENZYMES SYNTHESIS}

\author{
Mateus Cabral Vasconcellos Teixeira ${ }^{1}$ \\ Ester Helena Alves ${ }^{2}$ \\ Fabíola Pisciotta de Oliveira ${ }^{3}$ \\ Lucas Silva Vaz ${ }^{4}$ \\ Vânia Battestin Wiendl ${ }^{5}$
}

\begin{abstract}
Resumo: A produção de enzimas por meio de processos de fermentação sólida tem apresentado renovado interesse nos últimos anos, principalmente nos tempos atuais, em que se busca tecnologias mais limpas que diminuam o impacto sobre o meio ambiente. Existem poucos dados na literatura que tratam da automação de reatores para a fermentação sólida. Nesse tipo de fermentação existem a dificuldade de avaliar e controlar os principais parâmetros que estão envolvidos no processo, principalmente, $\mathrm{pH}$, temperatura, agitação e umidade do meio. Observando esse cenário, o objetivo deste trabalho foi a ampliação de escala e automação de parâmetros de temperatura e agitação do processo biotecnológico de produção de enzima tanase. O projeto da pá mecânica foi realizado com auxílio do software AutoCAD (Autodesk, EUA), e desenvolvido através de processo de torneamento com material de polipropileno. Para a automação do reator foi utilizado um Controlador Lógico Programável (CLP) e uma placa de driver contendo o circuito integrado ULN2003. O CLP foi programado utilizando o Software Clikedit-02 para controlar a rotação do motor durante a fermentação. A temperatura do processo foi monitorada através de um termopar tipo JK. Os resultados obtidos indicaram que uma alta intensidade de agitação no meio de fermentação pode prejudicar a produção da enzima $(0,02 \mathrm{U} / \mathrm{mL})$, sendo que agitações mais brandas favorecem a produção $(0,041 \mathrm{U} / \mathrm{mL})$. Conclui-se que a utilização de agitação no meio fermentativo auxilia para homogeneização do calor oriundo do metabolismo microbiano na produção da enzima tanase, porém, percebeu-se que agitações muito intensas e vigorosas diminuem a atividade enzimática.
\end{abstract}

Palavras-chave: Automação; enzimas; fermentação.

Abstract: Cleaner technologies that lessen the impact of industrial processes upon the environment have been increasingly sought. In recent years the production of enzymes by solid fermentation processes has awoken renewed interest. However, there are few data in the literature depicting the automation of reactors for solid fermentation. The main parameters that are involved in the process, mainly $\mathrm{pH}$, temperature, agitation and humidity of the medium, have been shown difficult to be measured and controlled. The objective of this work was to automate a solid fermentation reactor by the development of a stirring system (mechanical shovel) and internal temperature control during fermentation. A mechanical shovel cutout was designed using the software AutoCAD (Autodesk, USA), and molded through a lathe of the polypropylene material. For the automation of the reactor a Programmable Logic Controller (PLC) and a driver board containing the ULN2003 integrated circuit were used. CLP was programmed using the

\footnotetext{
1 Biólogo e graduando em Licenciatura em Química, Instituto Federal de Educação Ciência e Tecnologia de São Paulo - Campus São José dos Campos, Brasil. E-mail: mateuscabral1989@bol.com.br.

2 Licenciatura em Química, Instituto Federal de Educação Ciência e Tecnologia de São Paulo, Brasil. E-mail: esterhelena15@gmail.com.

${ }^{3}$ Licenciatura em Química, Instituto Federal de Educação Ciência e Tecnologia de São Paulo, Brasil. E-mail: fapisciotta@gmail.com.

4 Licenciatura em Química, Instituto Federal de Educação Ciência e Tecnologia de São Paulo, Brasil. E-mail: lucass.vaz98@gmail.com.

5 Doutora em Ciência dos Alimentos e Docente do Instituto Federal de Educação Ciência e Tecnologia de São Paulo, Campus São José dos Campos, Brasil. E-mail: vbattestin@ifsp.edu.br.
} 
software Clikedit-02 to control the rotation of the motor during fermentation and the process temperature was monitored by a JK-type thermocouple. The results indicated that a high intensity of agitation in the fermentation medium may impair the production of the enzyme $(0.02 \mathrm{U} / \mathrm{mL})$, while milder agitation favors a higher production $(0.041 \mathrm{U} / \mathrm{mL})$. It is concluded that the use of agitation in the fermentation medium assists in the release of heat from the microbial metabolism during the production of the enzyme tannase; however, it was noticed that very intense and vigorous agitation decreases the enzymatic activity.

Keywords: Automation; enzymes; fermentation.

\section{INTRODUÇÃO}

A produção de enzimas por meio de processos de FES (fermentação em estado solido) tem se mostrado muito interessante, já que nos tempos atuais há busca por tecnologias mais limpas que diminuam o impacto sobre o meio ambiente. O processo de FES pode ser descrito como crescimento de microrganismos sobre substratos com mínima presença de água livre. Dois substratos podem ser usados nesse processo, um servindo apenas como fonte de energia e outro servindo como fonte de carbono e energia (ROCHA, 2010; COSTA 2012).

Nos últimos anos, a maioria dos artigos publicados sobre FES estão relacionados com a produção de metabólitos em escala de laboratório, porém, poucos estão relacionados à ampliação de escala do processo (FONSECA, 2012). Para ampliação de escala do processo são utilizados fermentadores conhecidos como biorreatores, definidos como recipientes que buscam simular as condições do habitat natural de determinados microrganismos para que ocorra a produção de materiais desejados. Biorreatores de FES podem ser de leito fixo, de bandeja, tambor rotativos, entre outros (ZANELATO, 2011). O uso de biorreatores em escala industrial diminui de forma considerável os custos da produção de enzimas, entretanto a remoção de calor e manutenção da umidade do substrato são obstáculos tecnológicos (FONSECA, 2012).

Os estudos de FES dividem-se em duas etapas: em menor escala podem ser realizados em placa de Petri, erlenmeyers ou em sacos plásticos de polietileno. Nessa escala, não há presença de aparelhos para agitação ou aeração forçada, são controladas apenas condições do substrato, do microrganismo, da solução inoculante e da temperatura, controladas com o uso de biorreatores, devendo prevenir entrada de organismos contaminantes e evitar a emissão do microrganismo utilizado, produtos e substrato para o ambiente. Além disso, a arquitetura interna deve promover aeração eficiente para levar oxigênio para o microrganismo, remover calor metabólico, manter a uniformidade do substrato, esterilização e recuperação da biomassa (AGUDELO, 2010).

\section{Fermentação sólida}

A produção de enzimas por meio de processos de fermentação sólida tem apresentado renovado interesse nos últimos anos, buscando tecnologias mais limpas que diminuam o impacto sobre o meio ambiente. Um Processo de Fermentação em 
estado sólido (FES) pode ser descrito como o crescimento de microrganismos em substratos sólidos na ausência de água livre circulante no meio (BATTESTIN; MACEDO, 2007). Existem poucos dados na literatura que tratam da ampliação de escala para esse processo, bem como, automação de parâmetros da fermentação.

Os processos de fermentação sólida atualmente são projetados para uma escala laboratorial e o aumento da escala significa avaliar e controlar os principais parâmetros que estão envolvidos no processo, principalmente, $\mathrm{pH}$, temperatura, aeração, agitação e umidade do meio. O fator limitante para a ampliação de escala em processos industriais está diretamente relacionado às dificuldades de controlar e medir algumas das variáveis do processo. Não se consegue aumentar a escala de maneira simples e rápida com as mesmas condições e rendimentos. A ampliação de escala é uma limitação industrial e soluções tecnológicas são necessárias. Nesse sentido a ampliação de escala para produção de enzimas de interesse industrial tem se mostrado crescente (BERTUCCI-NETO et al., 2009a; TEIXEIRA et al., 2017a).

Cada processo necessita de caracterização, segundo propriedades físicas e biológicas, partindo de escalas de bancada até escalas maiores. As limitações de produtividade se devem à grande variabilidade espacial, no que diz respeito aos parâmetros físicos, que ocorrem no substrato. As soluções encontradas para crescimento da biomassa são variadas, incluindo reatores de bandeja, colunas, e tambor rotativo. Por sua vez, a instrumentação necessária para cada processo se reveste cada vez mais de importância, dada a rapidez com que a tecnologia de sensores, aquisição de dados, e programação de dados avança nos dias atuais. A aplicação de novos conceitos de reatores, e de instrumentação para controle e monitoração de processos é indispensável para o avanço do conhecimento existente em busca de escalonamento. A automação é imprescindível para o controle do processo sendo útil, também, para caracterização dos fenômenos que ocorrem no processo, quando aliado à modelagem. Dessa forma, podem ser interligados vários sensores coletando dados ao mesmo tempo, que serão usados para tomar decisões de controle do sistema, de forma manual, ou automática (BERTUCCI-NETO et al., 2009b).

\section{Enzima tanase}

A enzima tanase é uma enzima com grande aplicação industrial. Por definição, as tanases (E.C: 3.1.1.20) são esterases que hidrolisam ligações éster e ligações depsídicas em substratos como ácido tânico, epicatequina galato, epigalocatequina galato em meio aquoso e sintetizam ésteres de ácido gálico em meio não aquoso. Enzimas são empregadas em diversos setores industriais, contudo sua utilização é frequentemente limitada, devido ao seu baixo rendimento (BATTESTIN; PINTO; MACEDO, 2007; ISHIMOTO; SOARES; BATTESTIN, 2013; TEIXEIRA et al., 2017b). Atualmente a tanase é suprida no mercado brasileiro apenas via importação e constitui um produto de alto valor agregado. 
Vários estudos têm sido conduzidos em relação à produção e aplicações dessa enzima. A tanase pode ser utilizada na produção de antioxidantes (BATTESTIN; MACEDO; FREITAS, 2008; MACEDO et al., 2011), no melhoramento de rações para animais, potencializar as propriedades antioxidantes e propriedades anticancerígenas do suco de laranja (MADEIRA, 2014). A enzima pode ser ainda utilizada na biotransformação de compostos fenólicos no extrato hidrossolúvel de soja, obtendo um produto rico em compostos antioxidantes, sugerindo sua utilização como ingrediente para bebidas funcionais (QUEIRÓS, 2014).

O uso e produção de enzimas em diferentes áreas mostram perspectivas futuras promissoras devido às várias características inerentes à ação das enzimas que são compostos naturais, biodegradáveis, capazes de desempenhar reações específicas sem produzirem produtos secundários. Enzimas são excelentes catalisadores biológicos, contudo sua aplicação industrial pode ser limitada, devido a diversos fatores, como: custo de produção, alta solubilidade em água, menor estabilidade, quando comparadas com catalisadores químicos; baixa atividade a temperaturas elevadas e não ser viável sua recuperação após a utilização (AGUILAR; SANCHES, 2001).

Assim, esse trabalho teve como objetivo a ampliação de escala e automação de parâmetros de temperatura e agitação do processo biotecnológico de produção de enzima tanase.

\section{MATERIAIS E MÉTODOS}

\subsection{Microrganismos}

Foi utilizado o fungo da linhagem LAB1WW, extraído e isolado de casca da árvore conhecida popularmente como Ingá. O microrganismo pertence à coleção do Laboratório de Bioquímica e Microbiologia do Instituto Federal de São Paulo, Campus São José dos Campos. Posteriormente, esse fungo foi identificado pela Fundação André Tosello (Campinas/SP) através de análise molecular, sendo este o fungo Aspergillus niger.

\subsection{Preparo do pré inóculo}

As linhagens fúngicas foram repicadas em meio inclinado PDA (potato dextrose agar) com suplemento de $0,2 \%(\mathrm{p} / \mathrm{v})$ de ácido tânico $(\mathrm{pH}$ final do meio $=5,2)$, e incubadas em estufa à $32^{\circ} \mathrm{C}$ por $72 \mathrm{~h}$, para pré-indução da tanase. O pré-inóculo é a etapa que antecede à fermentação sólida.

\subsection{Meio de fermentação sólida para a produção da enzima tanase}

Em frascos erlenmeyers de $250 \mathrm{~mL}$ foram adicionados $10 \mathrm{~g}$ de farelo de trigo e $10 \mathrm{~mL}$ de solução de sais na concentração (g/L): $\mathrm{NH} 4 \mathrm{Cl}$ 0,1.; (NH4)2SO4 0,1; $\mathrm{CaCl} 2.2 \mathrm{H} 2 \mathrm{O}$ 0,01; K2SO4 0,01; MnSO4.H2O 0,002; FeSO4.7H2O 0,002. O indutor ácido tânico foi adicionado ao meio de fermentação na concentração final de $5 \%$. 0 
meio de cultivo foi esterilizado a $120^{\circ} \mathrm{C}$ por 20 minutos, com umidade relativa $60 \%$ (BU) e pH 5,8. Após a esterilização os frascos foram inoculados com 2,5 mL de solução de esporos e incubados a $32^{\circ} \mathrm{C}$ em estufa, por 5 dias. Após fermentação, foram adicionados $70 \mathrm{~mL}$ de solução tampão acetato de sódio $(\mathrm{C} 2 \mathrm{H} 3 \mathrm{NaO} 2) \mathrm{com} \mathrm{pH}$ $5,0-20 \mathrm{mM}$ e agitados a $150 \mathrm{rpm}$ por 90 minutos. A solução foi filtrada em algodão e o filtrado centrifugado a $3000 \mathrm{rpm}$ por 15 minutos. No sobrenadante foi medida a atividade enzimática da tanase (LEKHA; LONSANE, 1994). Para a projeção de aumento de escala, utilizou-se um reator de $1000 \mathrm{~mL}$, sendo assim, a quantidade e concentração de reagentes e materiais necessários para preparar o meio de fermentação foram aumentadas proporcionalmente ao aumento do reator.

\subsection{Medida da atividade enzimática da tanase}

A solução de substrato foi preparada pela adição de $0,12 \%(p / v)$ de ácido tânico em tampão acetato de sódio $(\mathrm{C} 2 \mathrm{H} 3 \mathrm{NaO} 2) \mathrm{com} \mathrm{pH}$ 5,5 - 0,2 M. A reação foi realizada adicionando $0,3 \mathrm{~mL}$ da solução de substrato com $0,5 \mathrm{~mL}$ de extrato enzimático bruto e incubado a $60 \mathrm{oC}$ por 10 minutos. Após a incubação, a reação foi paralisada pela adição de $3 \mathrm{~mL}$ de solução de BSA preparada na concentração de $1 \mathrm{mg} / \mathrm{mL}$ de albumina de soro bovino (BSA) e 0,17 M de cloreto de sódio em tampão acetato de sódio $(\mathrm{C} 2 \mathrm{H} 3 \mathrm{NaO} 2) \mathrm{com} \mathrm{pH} 5,0,0,2 \mathrm{M}$. Em seguida a solução foi centrifugada a 3000 rpm por 10 minutos. O precipitado foi ressuspenso em $3 \mathrm{~mL}$ de solução SDStrietanolamina acrescido de $1 \mathrm{~mL}$ de solução de $\mathrm{FeCl}$. A absorbância foi medida após 15 minutos em $530 \mathrm{~nm}$ (MONDAL et al, 2001). A curva padrão foi elaborada utilizando quantidades de ácido tânico comercial variando entre $0,01 \%$ e $0,15 \%$. A atividade enzimática foi calculada pela diferença da leitura de absorbância medida a $530 \mathrm{~nm}$ entre amostra e tubo controle. Uma unidade de atividade de tanase foi definida como a quantidade de ácido tânico hidrolisado por $\mathrm{mL}$ de enzima empregada por minuto de reação:

$$
\begin{aligned}
& A b s_{530}=A b s_{\text {controle }}-A b s_{\text {teste }} \cdot \quad \text { (Equação 1) } \\
& \text { Onde: } A b s_{\text {teste }}=\text { substrato + enzima ativa } \\
& A b s_{\text {controle }}=\text { substrato + enzima desnaturada }
\end{aligned}
$$

\subsection{Desenvolvimento do sistema mecânico para o reator de fermentação}

O projeto mecânico foi desenvolvido e analisado com auxílio do software AutoCAD (Autodesk, EUA). A construção da pá e demais componentes necessários para acoplamento e construção do sistema de agitação do reator foi desenvolvido no laboratório de mecânica do Campus São José dos Campos, por meio de processo de torneamento com material de polipropileno. O formato escolhido para o impelidor foi o de pás retas, com dimensões de $10 \mathrm{~cm}$ de comprimento $\times 2,5 \mathrm{~cm}$ de altura. $O$ impelidor foi projetado de acordo as dimensões do reator de $1000 \mathrm{~mL}$. 


\subsection{Automação do reator de fermentação}

Há uma escassez de dados na literatura que tratam de automação de reatores para fermentação sólida, dessa forma, o sistema de automação, desenvolvido nesse trabalho, consistiu em realizar a programação de rotação do motor e o sistema de agitação através de um Controlador Lógico Programável (CLP). Foram utilizados um CLP e uma placa de driver contendo o circuito integrado ULN2003. O CLP foi programado utilizando o Software Clikedit-02 para controlar a rotação do motor durante a fermentação e a temperatura do processo foi monitorada através de um termopar tipo JK. Inicialmente, as agitações dentro do reator foram programadas para rotacionar a 10rpm durante 2 min ininterruptos. Dessa forma, o sensor de temperatura, que estava acoplado dentro do reator, captava dados da temperatura do meio de fermentação durante o período de agitação, informando e registrando as novas temperaturas desse meio. Com esse mecanismo foi possível monitorar os decréscimos de temperatura, e estas foram registradas e armazenadas no dispositivo de detecção. Posteriormente, o escalonamento de agitação passou a operar uma e duas vezes ao dia durante 2 min ininterruptos (sempre na condição fixa de 10rpm). Com isso, pode-se monitorar a influência da quantidade de agitações no meio de fermentação e inferir se isto poderia influenciar na produção da enzima, através da dissipação de calor proveniente do metabolismo microbiano.

\section{RESULTADOS E DISCUSSÂO}

\subsection{Produção da enzima em reatores de diferentes tamanhos}

A grande maioria dos estudos em relação à produção da enzima tanase referemse à produção da enzima utilizando reatores de bancada de $250 \mathrm{~mL}$ ou $300 \mathrm{~mL}$. Ensaios realizados nesses reatores implicam em fácil execução, menor gasto de reagentes e maior facilidade de adaptação desse tipo de reator em laboratórios de pesquisa.

No presente estudo foi utilizado um reator de $250 \mathrm{~mL}$ e outro de tamanho 4 vezes maior (1000 $\mathrm{mL}$ ), todos em duplicatas. Para ambos, seguiu-se a metodologia de produção e determinação da atividade enzimática de tanase de acordo ao item $2.3 \mathrm{e}$ 2.4. A Figura 1 apresenta os resultados da atividade de tanase obtida após 3 dias de fermentação, utilizando o farelo de trigo como substrato.

Observou-se que a atividade da enzima no reator de $250 \mathrm{~mL}$ foi de $0,034 \mathrm{U} / \mathrm{mL}$, enquanto que no reator de $1000 \mathrm{~mL}$, a atividade foi de $0,041 \mathrm{U} / \mathrm{mL}$. Ao se projetar a produção enzimática em reatores maiores, espera-se que a atividade seja mantida igual ou maior que nos testes com reatores menores, neste caso, de $250 \mathrm{~mL}$. 
Figura 1 - Atividade da enzima tanase e reatores de tamanhos diferentes.

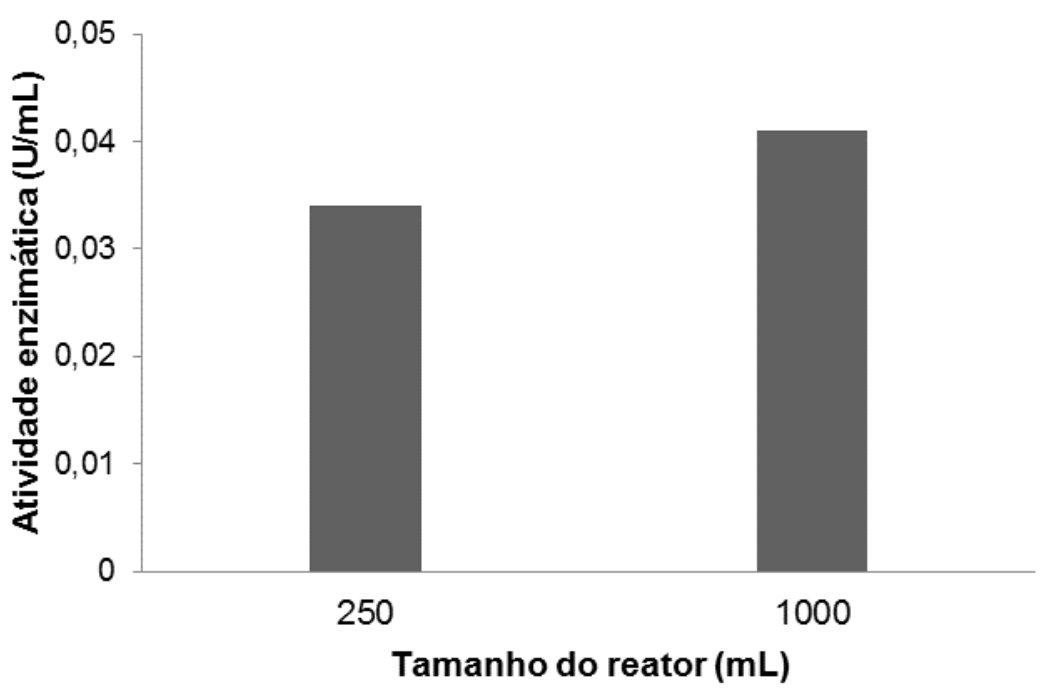

Fontes: Os autores.

\subsection{Estudos de fermentação com o reator automatizado}

A partir desse momento, os estudos de produção da enzima foram conduzidos em reator de $1000 \mathrm{~mL}$. O reator automatizado, com controle de temperatura, encontrase na Figura 2. Nesse sistema, um sensor de temperatura interna captava dados da temperatura do meio de fermentação durante a agitação dentro do reator. Através de um controlador lógico programável (CLP) foram conduzidas agitações dentro do reator, operando a $10 \mathrm{rpm}$ durante $2 \mathrm{~min}$ ininterruptamente. As variáveis, coletadas pelo sistema de automação do reator, mantiveram-se as mesmas.

Figura 2 - Sistema de agitação e controle de temperatura interna do reator, utilizando o CLP para controlar as variáveis do processo.

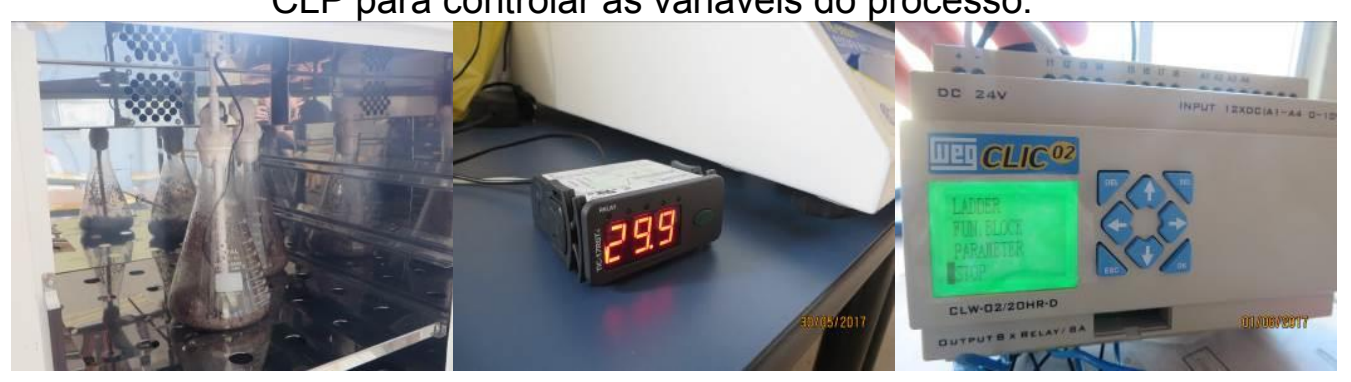

Fonte: Os autores.

\subsection{Influência da agitação no meio de fermentação e produção da enzima}

Durante a fermentação microbiana há um aumento da temperatura interna do substrato devido ao metabolismo do fungo por produzir gases e calor. Dependendo da quantidade de calor que é formada nesse processo, pode ocorrer uma diminuição da produção da enzima dentro do reator, sendo este, um fator negativo. De acordo com Schmidell e Facciotti (2001) e Yao et al. (2018) é importante que ocorra um controle 
desse calor no processo de fermentação solida, desta forma, é essencial que exista um mecanismo para dissipar ou diminuir a temperatura interna no reator. Neste trabalho, utilizou-se um sistema de agitação com uma pá mecânica, rotacionando dentro do reator, sendo esta agitação controlada pelo CLP. A Figura 3 mostra os resultados obtidos, para a produção da enzima, utilizando agitações no meio de fermentação duas vezes ao dia a uma velocidade de $10 \mathrm{rpm}$.

Figura 3 - Influência da agitação utilizando velocidade de 10 rpm no meio de fermentação.

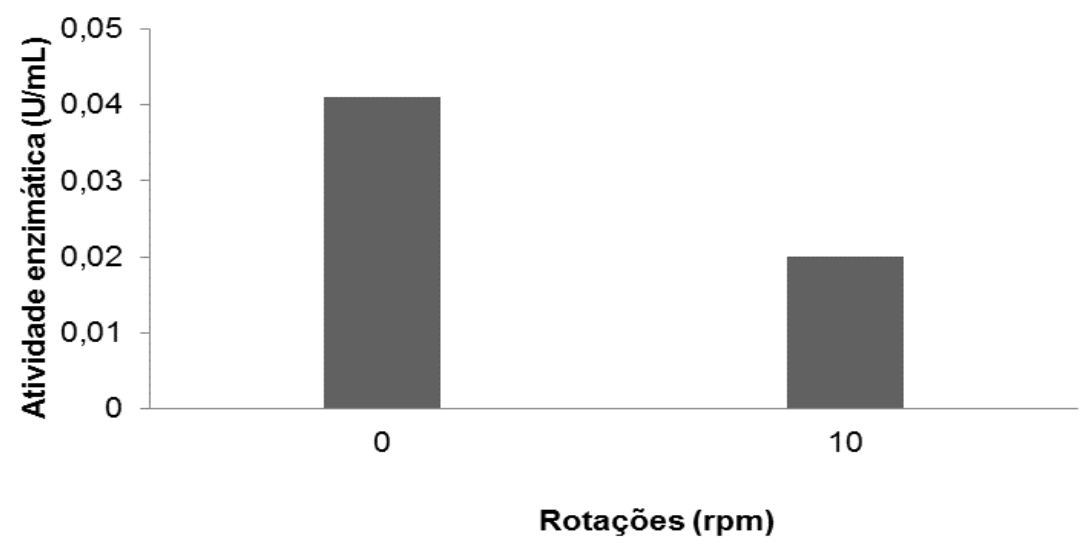

Fonte: Os autores.

Foi possível observar que durante a fermentação ocorreu um aumento da temperatura no substrato devido aos processos metabólicos do microrganismo. A temperatura passou de $31^{\circ} \mathrm{C}$ para $33^{\circ} \mathrm{C}$. Com o sistema de agitação operando a 10 rpm, duas vezes ao dia, a temperatura interna do substrato baixou para $30^{\circ} \mathrm{C}$. Esse processo permitiu a circulação do ar, transferência de massa e troca de calor formado durante a fermentação. Para esse sistema, foi obtida uma atividade enzimática de 0,02 $\mathrm{U} / \mathrm{mL}$. Esse valor de atividade foi menor quando comparado ao sistema controle, onde não ocorreu nenhum processo de agitação. $O$ valor de atividade enzimática obtido para reator controle foi de $0,041 \mathrm{U} / \mathrm{mL}$.

A partir desses resultados, projetaram-se novos experimentos. A Figura 4 apresenta os resultados da produção da enzima, utilizando uma velocidade de rotação de 10rpm, acionada uma e duas vezes ao dia, durante 3 dias de fermentação. 
Figura 4 - Influência do número de agitações na rotação 10 rpm.

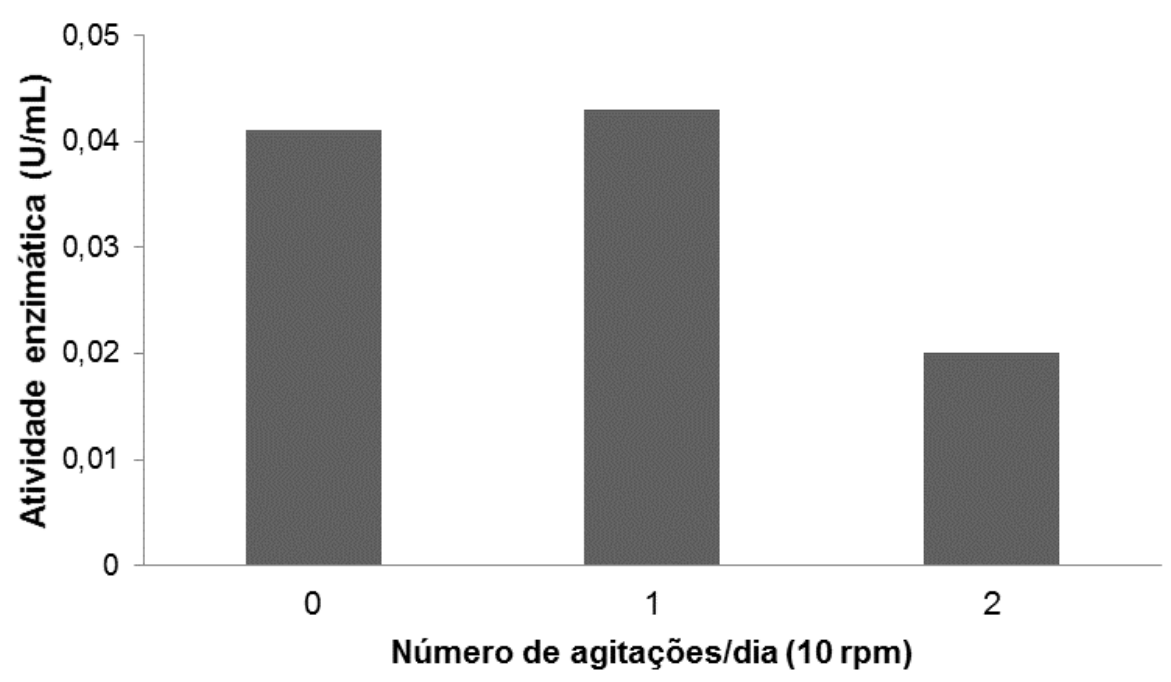

Fonte: Os autores.

Percebeu-se que o número de agitações no meio de fermentação (aplicando nenhuma, uma e duas agitações durante 2 min ininterruptos), exerceram respostas distintas na produção da enzima. Ao diminuir o número de agitações de duas para uma agitação (rotação fixa em $10 \mathrm{rpm}$ ) durante os 3 dias de fermentação, a produção da tanase foi aumentada. A melhor atividade enzimática foi de $0,041 \mathrm{U} / \mathrm{mL}$ observada quando se utilizou uma agitação/dia, ao passo que, com duas agitações/dia a atividade enzimática baixou para $0,02 \mathrm{U} / \mathrm{mL}$. Supõe-se que essa diminuição de atividade enzimática tenha ocorrido devido à liberação excessiva de umidade do meio de fermentação, sendo este um parâmetro importante que influencia no processo da fermentação em estado sólido (BERTUCCI-NETO et al., 2009b). Segundo Del Bianchi et al. (2001) e Hölker, Höfer e Lenz (2004) a umidade no substrato em quantidades adequadas ajudará na transferência de nutrientes e de oxigênio, porém se o teor de umidade for alto demais, acabará prejudicando o meio e assim diminuindo as trocas gasosas, aumentando a temperatura interna. Entretanto, se a umidade for relativamente baixa irá prejudicar o crescimento do microrganismo, consequentemente influenciará no produto final de interesse.

Segundo Abrunhosa \& Venâncio (2007) e Oliveira Júnior (2014) que investigaram vários efeitos na produção de enzimas produzidas por Aspergillus fumigatus, constataram que a umidade do substrato demonstrou ser um parâmetro importante para a síntese enzimática. Esses dados corroboram com Rocha (2010), que estudou a otimização da produção de enzimas, produzidas por Aspergillus niger e também constatou que a umidade é um parâmetro importante para a síntese de biomoléculas. Os fungos são mais tolerantes a baixas umidades, se comparados às bactérias.

Além da umidade, o mecanismo de agitação pode interferir no desenvolvimento 
do fungo, pois a mistura constante leva a fragmentação mecânica do micélio, podendo causar compactação do meio e a danificação das hifas. Fungos filamentosos são particularmente susceptíveis a estas forças, suas hifas aéreas são esmagadas sobre a superfície do substrato, resultando em inibição da esporulação (CORREIA, 2004).

\section{CONCLUSÕES}

Observou-se a importância da agitação do meio de fermentação para a homogeneização da temperatura do meio e do aumento da troca de calor com as paredes do recipiente. Porém, percebeu-se que agitações muito intensas e vigorosas diminuem a atividade enzimática, pois muito provavelmente a umidade do meio de fermentação foi bastante reduzida, prejudicando o metabolismo microbiano para a síntese de proteína. Contudo, percebeu-se a influência positiva de um mecanismo de agitação dentro do fermentador, agitações menos intensas e vigorosas favorecem a produção da enzima pelo microrganismo, se comparado ao reator sem agitação. Mais estudos são indicados para elucidar quais os parâmetros ideais de agitação/tempo são importantes para a síntese da enzima.

\section{REREFÊNCIAS}

ABRUNHOSA, L.; VENÂNCIO, A. Isolation and purification of an enzyme hydrolyzing ochratoxin A from Aspergillus niger. Biotechnology letters, v. 29, n. 12, p. 1909-1914, 2007.

AGUDELO, L. M. G. Avaliação de um biorreator rotativo para fermentação em estado sólido. Dissertação (Mestrado em Engenharia Química) - Universidade Estadual Paulista Júlio de Mesquita Filho, São José do Rio Preto, 2010.

AGUILAR, C.N.; SANCHES, G. Review: sources, properties, applications and potential use of tannin acyl hydrolase. Food Science and Technology International, v. 7, n. 5, p. 373-382, 2001.

BATTESTIN, V ; MACEDO, G . Tannase production by Paecilomyces variotii, Bioresource Technology, v. 98, n. 8, p. 1832-1837, 2007.

BATTESTIN, V.; PINTO, G. A. S.; MACEDO, G. A. Biochemical characterization of tannases from Paecilomyces variotii and Aspergillus niger. Food Science and Biotechnology, v. 16, n. 2, p. 243-248, 2007.

BATTESTIN, V.; MACEDO, G.; FREITAS, V. A. P. Hydrolysis of epigallocatechin allate using a tannase from Paecilomyces variotii. Food Chemistry, v. 108, n. 1 p. 228-233, 2008.

BERTUCCI-NETO, V. et al. Controle automático de fluxo e ajuste de umidade do ar de alimentação em reatores de fermentação sólida. In: SIMPÓSIO NACIONAL DE BIOPROCESSOS, 17, 2009. Natal. Anais..., Natal: UFRN, 2009a. 
BERTUCCI-NETO, V. et al. Automação de reatores de fermentação sólida para produção de enzima. 1.ed. São Carlos: Embrapa Instrumentação Agropecuária, 2009b.

CORREIA, R.T.P. Estudo do cultivo semi-sólido em resíduos de abacaxi por Saccharomyces cereviseae e Rhizopus oligosporus. Tese (Doutorado em Engenharia Química) - Departamento de Engenharia Química, Universidade Federal do Rio Grande do Norte, 2004.

COSTA, P. N. Otimização da produção da tanase por Aspergillus sp. em fermentação em estado sólido (FES). Dissertação (Mestrado em Microbiologia Agrícola) - Universidade Federal de Lavras, Lavras, 2012.

DEL BIANCHI, V. L. et al. Biotecnologia industrial: engenharia bioquímica., São Paulo: Edgard Blücher Ltda, 2001, v. 2, p. 247-276.

FONSECA, R. F. Sistema de controle de fluxo, temperatura e umidade relativa do ar para processos de fermentação em estado sólido. Dissertação (Mestrado em Ciências) - Universidade de São Paulo, São Carlos, 2012.

HÖLKER, U.; HÖFER, M.; LENZ, J. Biotechnological advantages of laboratory-scale solid-state fermentation with fungi. Applied microbiology and biotechnology, v. 64, n. 2, p. 175-186, 2004.

ISHIMOTO, C. K.; SOARES, C. F.; BATTESTIN, V.; Isolamento e seleção de microrganismos de fontes naturais da região de São Roque, SP, para produção da enzima tanase. Scientia Vitae, v.1, n. 1, p. 43-19, 2013.

LEKHA, P. K.; LONSANE, B. K. Comparative titres, location and properties of Tannin Acyl Hydrolase produced by Aspergillus niger PKL 104 in solid-state, liquid surface and submerged fermentations. Process Biochemistry, v.29, n. 6, p. 497-503, 1994.

MACEDO, J. A. et al. Increasing the antioxidant power of tea extracts by biotransformation of polyphenols. Food Chemistry, v. 126, n. 2, p. 491-497, 2011.

MADEIRA, J. V. J. Produção de tanase obtenção de compostos fenólicos através da biotransformação por Paecilomyces variotii a partir de resíduos de Citrus. Tese (Doutorado em Ciências de Alimentos) - Faculdade de Engenharia de Alimentos, Universidade Estadual de Campinas, Campinas, 2014.

MONDAL, K.C. et al. Colorimetric Assay Method for determination of the Tannin Acyl Hidrolase (EC 3.1.1.20) activity. Analytical Biochemistry, v. 295, n. 2, p. 168-171. 2001.

OLIVEIRA JUNIOR, S. D. Produção de enzimas por fungos em fermentação semisólida utilizando bagaço de coco e pedúnculo de caju como substratos. Dissertação (Mestrado em Engenharia Química) - Departamento de Engenharia Química, Universidade Federal do Rio Grande do Norte, 2014.

QUEIRÓS, L. D. Biotransformação de compostos fenólicos do extrato de soja para obtenção de produto rico em compostos bioativos. Dissertação (Mestrado em Ciências de Alimentos) - Faculdade de Engenharia de Alimentos, Universidade Estadual de Campinas, Campinas, 2014. 
ROCHA, C. P. Otimização da produção de enzimas por Aspegillus niger em fermentação em estado sólido. Dissertação (Mestrado em Engenharia Química) Universidade Federal de Uberlândia, Uberlândia, 2010.

SCHMIDELL, W.; FACCIOTTI, M. C. R. Biorreatores e Processos Fermentativos. In: Schmidell, Willibaldo et al. (Coord.). Biotecnologia Industrial: Engenharia Bioquímica. São Paulo: Edgar Blücher, 2001. p. 179-192.

TEIXEIRA, M.C.V. et al. Automation of a solid fermentation reactor for enzymes production. In: SIMPÓSIO LATINO AMERICANO DE CIÊNCIAS DE ALIMENTOS, 12, 2017, Campinas. Anais..., Campinas: GALOÁ, 2017a.

TEIXEIRA, M.C.V. et al. Tannase production by Aspergillus niger isolated from ingá soil. In: SIMPÓSIO LATINO AMERICANO DE CIÊNCIAS DE ALIMENTOS, 12, 2017, Campinas. Anais..., Campinas: GALOÁ, 2017b.

YAO, K. Y. et al. Upgrading of by-product from beverage industry through solid-state fermentation with Candida utilis and Bacillus subtilis. Letters in applied microbiology, v. 67, n. 6 , p. 557-563, 2018.

ZANELATO, A. I. Produção de enzimas celulolíticas por fermentação em estado sólido em biorreator em leito fixo. Dissertação (Mestrado em Engenharia de Alimentos) - Universidade Estadual Paulista “Julio de Mesquita Filho", São José do Rio Preto, 2011. 